\title{
List of Appendices
}

2.I The Heritage Audience Survey Questionnaire $\quad$ I84

2.2 Demographic profile of the National Trust (NT) membership $\quad$ I93

2.3 Demographic profile of the Time Out (TO) readership $\quad 194$

The Heritage Audience Survey sample

3.I Age/gender distribution of the NT and TO cohorts compared to the overall UK cinemagoing population (1994) $\quad$ I96

3.2 Age/gender distribution of the NT and TO cohorts compared to UK cinema audiences for selected period feature-film releases (I994 and I992)

3.3 ABCi socio-economic class of respondents (by household) compared to the overall UK cinemagoing population (1994)

3.4 ABCi socio-economic class of respondents (by household) compared to UK cinema audiences for selected period feature-film releases (1994 and 1992)

3.5 Nationality and race/ethnicity of respondents

3.6 UK regions where respondents lived at the date of completing the questionnaire

3.7 Analysis of neighbourhood types where respondents lived

5. I Classificatory groupings used in analysis of respondents' period film tastes

5.2 Hierarchies of period film taste among the NT and TO survey cohorts

6.I Hierarchies of period film pleasures among the NT and TO survey cohorts 